\title{
A esfera simbólica da produção: estratégias de publicização do mundo do trabalho na mídia digital
}

Vander Casaqui

\section{Resumo:}

As estratégias de representação do mundo do trabalho são analisadas nesse trabalho, na tradução do sistema produtivo da cerveja Bohemia para o meio digital, em função do universo simbólico de sua marca. Dessa forma, a Fábrica Bohemia, espaço virtual que é objeto da análise, é uma construção discursiva da produção de cerveja para sustentar e ampliar as significações intangíveis da mercadoria. Essa versão midiática da produção é reificada, mercadorizada para o consumo simbólico a partir de processos de publicização - conceito que amplia o sentido da publicidade como mensagem de fundo comercial restrita a espaços delimitados de veiculação.

\section{Palavras Chave:}

consumo; publicização; mídia digital; mundo do trabalho; comunicação

\begin{abstract}
:
This article analyzes the strategies that represent the work environment through the study of the transposition of Bohemia's productive system to a digital media. The virtual Bohemian Factory, the object of this study, is a discursive construction of beer production that sustains and amplifies the good's intangible significations. This mediatic version of production is reified, merchandized to symbolic consumption by means of publicization processes - a concept that amplifies the sense of publicity from its original understanding as commercially based messages restricted to specific spaces of distribution.
\end{abstract}

\section{Keywords:}

consumption; publicization; digital media; work world; communication

\section{Publicidade, publicização e trabalho}

Na cena contemporânea, os processos comunicacionais das mercadorias se disseminam para além do espaço concedido pela mídia tradicional à publicidade. Intervalos comerciais nos entremeios da programação televisiva, anúncios a fragmentar o conteúdo de publicações impressas, promoções de marcas e produtos incorporados a programas de auditório e de variedades, entre outros formatos convencionais de divulgação mercadológica, não são as únicas formas de tornar públicas as ofertas da sociedade de consumo. Daí a necessidade de expandirmos o conceito de publicidade - historicamente caracterizado, a partir do século XX, como a comunicação de fundo comercial veiculada em espaços específicos para tal fim - para o conceito de publicização, mais ajustado à multiplicidade de formatos e estratégias a partir dos quais as mercadorias, as marcas e as instituições tornam-se públicas, são comunicadas, são postas em cena para o consumo simbólico. De acordo com Vera França (2006: 82), “o ato de publicizar (disponibilizar informações, imagens, narrativas) atualiza um sistema de regras de seleção, de modos de participação". O conceito de publicização é uma ampliação conceitual que abarca, 
além da publicidade tradicional, os elementos da comunicação das marcas que dificilmente são lembrados quando se discutem as estratégias da comunicação mercadológica, apesar do seu incontestável papel de promover o universo simbólico das marcas, como formas de aprofundamento das relações do consumidor com esse universo. De forma cada vez mais presente, a internet tem servido como plataforma de propostas de consumo que instauram sujeitos da comunicação em interação e em experiência, "afetando e sendo afetados tanto pela co-presença como pela mediação simbólica que os institui em pólos de uma interação" (FRANÇA, 2006: 83-4).

O caráter do consumo que transcende a aquisição de produtos, por ser incorporado à prática cotidiana da comunicação, ajusta-se ao entendimento da comunicação como interação; dessa forma, consumimos e produzimos discursos, afetamos e somos afetados continuamente, instauramos a nós mesmos como sujeitos da comunicação e somos instaurados por outros discursos, compondo cadeias discursivas, novos fios nas tramas dialógicas que compõem a cultura de nosso tempo (BAKHTIN, 1997; FRANÇA, 2006). Destacamos aqui nosso entendimento do caráter indissociável do binômio comunicação e cultura: "um projeto de cultura pressupõe um projeto comunicativo, mas também todo projeto de comunicação trama junto seu projeto de cultura" (BAITELLO JÚNIOR, 2005: 8).

Marx sugere a importância da comunicação no interior do sistema produtivo, como etapa necessária de divulgação a fim de tornar possível o consumo. Nas palavras do autor, o possuidor das mercadorias é "obrigado a meter sua língua na cabeça delas ou lhes pendurar pedaços de papel" para anunciá-las (MARX, 2004: 38); essa função da comunicação deve ser entendida de forma ampla na cultura de consumo contemporânea, uma vez que o processo de publicização é municiador de atributos intangíveis, que inserem as mercadorias no contexto das ações, relações, interações humanas, no diálogo com os discursos e com o "espírito" de seu tempo.

É na confluência da comunicação e da cultura que tratamos a questão do mundo do trabalho, uma vez que a discussão proposta tem como enfoque as representações do sistema produtivo, da esfera de produção dos anunciantes, inseridas na sua publicização. O trabalho no seio do capitalismo contemporâneo é compreendido de forma complexa, pois engloba uma série de paradoxos. Oscila entre a alta tecnologia e o trabalho escravo; os altos salários para profissionais destacados e disputados, e as migalhas da informalidade, destinada aos que perderam lugar no mercado formal, ou nunca o obtiveram; a ampliação do espectro de atuação, com atividades inusitadas, inovadoras, percebidas no senso comum como fonte de realização por si só, e a permanência de velhas formas de exploração de mão de obra. São realidades que se imbricam, tanto na produção industrial sucateada da velha economia, quanto na mais sofisticada corporação, no que diz respeito aos recursos tecnológicos, associada principalmente ao capitalismo tardio ou flexível. Marx, ao olhar para o contexto de sua época, definiu o conceito de fetichismo da mercadoria como expressão da relação ambígua que os produtores, os trabalhadores incorporados à divisão do trabalho do sistema capitalista industrial, tinham com o fruto de seu trabalho; o estranhamento, o distanciamento da relação de identidade entre a atividade funcional e o produto final, resultado de inúmeros processos que fazem do trabalho especializado facilmente substituível e, ao mesmo tempo, restrito no que se refere a habilidades profissionais que sejam valorizadas no mercado. A força de trabalho como mercadoria vive das oscilações do capitalismo contemporâneo: momentos de entusiasmo, de aumento de vendas a requerem às pressas; etapas de crise e incerteza têm como medidas de urgência a redução de investimentos com os "recursos humanos", além da onipresente e sempre ameaçadora automatização persistir como promessa de extinção de postos e da presença humana na esfera da produção. O trabalho material e o imaterial coexistem no capitalismo global sob o qual vivemos, apesar da nítida diferenciação quando se pensa nos lucros e nos investimentos da nova economia: o trabalho imaterial, relacionado ao setor de serviços, tem sido mais prestigiado, de maneira geral. Como defende André Gorz: 
O fornecimento de serviços, esse trabalho imaterial, torna-se a forma hegemônica do trabalho; o trabalho material é remetido à periferia do processo de produção ou abertamente externalizado. Ele se torna um "momento subalterno" desse processo, ainda que permaneça indispensável ou mesmo dominante do ponto de vista qualitativo. O coração, o centro da criação de valor, é o trabalho imaterial (GORZ, 2005: 15).

As significações do consumo no capitalismo contemporâneo passam pela maneira como os processos produtivos e suas mercadorias resultantes são comunicados, colocados em circulação para consumo midiático, alimentando o imaginário de nossa época. Segundo Bauman (2001), a passagem do capitalismo pesado para o capitalismo leve, fluído, decretou um caráter de individualização, de esvaziamento do vínculo identitário e dos planos de carreira associados a instituições sólidas, centenárias. O trabalhador se instauraria como consumidor, a escolher entre as opções aquela que condiz com seus interesses e desejos mais íntimos de realização profissional e ambição material. Esse é o imaginário do neoliberalismo, colocado à prova pelo histórico do desemprego, que se intensifica a cada crise econômica global que surge em um ponto do globo e varre postos de trabalho em qualquer parte, além de renovar estimativas sombrias para inúmeros setores do chamado mercado, entidade igualmente abstrata e de concreta presença no cotidiano de todos nós.

E como a questão da mercadoria se coloca ante esse cenário? Este parece ser o campo da imanência, da transcendência, quando visto sob a ótica dos discursos identificados com o objetivo de seduzir os possíveis consumidores. Enquanto o noticiário e os informes corporativos falam de instituições que abrem seus números contábeis e anunciam sua fragilidade, suas incertezas e suas "justificativas" para cortes de funcionários, na esfera da publicização, a proposta é de transportar o consumidor para outro plano de percepção da realidade, compondo midiapanoramas (APPADURAI, 1999: 315-316), nos quais a marca recorta e dá significado aos elementos evocados do mundo em função de sua lógica. $\mathrm{O}$ arcabouço cultural e as práticas cotidianas são fonte inesgotável para a produção do editado mundo publicitário. A estética da mercadoria, conforme analisa Haug (1997), estabelece camadas que vão sobrepor-se aos produtos, imbricando-se a eles de maneira indissolúvel. As conotações das mercadorias são fundadas em sua contextualização na vida cotidiana; os cenários construídos da comunicação, tanto no design de um ambiente de loja, quanto na cena de um comercial televisivo, mantêm um vínculo com nossa percepção da realidade ao redor, mesmo quando procuram lhe dar novos sentidos, em um processo que se aproxima do conceito de ilusão referencial (BARTHES, 1994: 186).

A entrada em cena das marcas associando-se às novas tecnologias é uma forma de publicização, ao construir ambiências e propor experiências que permitem a amplificação do universo simbólico das mercadorias em elementos estéticos e conteúdos que edificam uma "síntese suja" dos mais diversos recursos e formatos já experimentados na cultura midiática, integrados nesse "novo espaço de encontro da humanidade com ela mesma" (PARENTE, 1999: 58). Essa visão que remete à natureza interacional da comunicação é o ponto a ser destacado em nossa abordagem da publicização no ciberespaço. As instituições, quando representadas na Internet, reconstroem a si mesmas, ao compor regimes de visibilidade, ou "modos de aparecer" (LANDOWSKI, 2002: 69), estrategicamente pensados em relação ao seu interlocutor ideal, o leitor modelo, ou o enunciatário que é projetado pelas tramas discursivas. As características próprias das linguagens do meio digital tornam mais arbitrário esse processo de tradução da maneira como as instituições querem parecer para um determinado público inserido em um contexto midiático específico. Para parte considerável dos usuários que interagem com a instituição somente a partir de seus modos de aparecer no meio digital, essa versão que se publiciza se sobrepõe, alimenta o imaginário em torno do que a empresa é:

Toda realidade mais ou menos complexa, problemática ou não, sempre se traduz em representações, imagens, metáforas, parábolas e alegorias, assim como em descrições e 
interpretações. E é por meio das linguagens que isto ocorre, envolvendo palavra, imagem, som, forma, movimento etc. Por isso é que os meios de comunicação colocam-se diretamente no âmago do mundo da cultura, das condições e possibilidades de representação e imaginação (IANNI, 2002: 132).

Ao recuperarmos a questão do fetichismo da mercadoria em Marx, discutimos a maneira como o caráter social do trabalho é esvaziado em função da reificação da mercadoria, personalizada e emancipada dos processos históricos que a concebem e do papel do trabalhador nesse processo. Fontenelle (2002: 284) utiliza o conceito de fetichismo das imagens para situar a temática no contexto da profusão da cultura imagética contemporânea, na qual os signos midiáticos remetem uns aos outros; o caráter referencial da linguagem pouco significa para além da auto-referência a essa espetacularização das imagens, que associamos ao processo de mercadorização da cultura analisado por Debord em $A$ sociedade do espetáculo. Nosso objeto se dá no entrecruzamento das duas questões, a partir da questão: quais os significados da tradução do mundo do trabalho para a cultura midiática?

Baudrillard destaca a importância da publicidade (ou, de acordo com nossa tese, dos processos de publicização) para a cultura contemporânea: menos pelo seu imperativo, ou o apelo à ação de uma comunicação específica; mais por sua função indicativa, de remeter a um cenário de humanização das mercadorias e ampliação de suas conotações, a ponto de alimentar o sistema no qual os objetos passam a nos consumir, a dispor de nossa ação, de nossa atenção e de nosso trabalho ao se inserir em nossas vidas (BAUDRILLARD, 2006). Sob esse aspecto, discutiremos, a seguir, sobre como os consumidores são demandados pela comunicação da Fábrica Bohemia.

\section{A Fábrica Bohemia e a instauração do consumidor-aprendiz}

A Fábrica Bohemia é intitulada "a primeira fábrica de cerveja virtual em 3D do mundo", como se pode ler na página de abertura de seu site na internet (http://www.bohemia.com.br/fabrica/index.html). Inaugurada no segundo semestre de 2008, a iniciativa é vinculada à marca da primeira cerveja do Brasil, a Bohemia, fabricada desde 1853, que hoje é de propriedade industrial da AmBev (Companhia de Bebidas das Américas), a $5^{a}$ maior cervejaria do mundo, com atuação em 14 países, 45 fábricas somente no continente americano, e cerca de 12 bilhões de litros de bebidas vendidos por ano, de acordo com dados da empresa (1).

A página inicial do site da Fábrica Bohemia apresenta, após o filtro para "identificar" se o internauta tem idade superior a 18 anos (2), a marca Bohemia, e logo abaixo o que seria o "discurso fundador" da visualidade explorada em todo o site: uma foto da fachada da Companhia Cervejaria Bohemia, a primeira fábrica que produziu a cerveja, em 1853. A foto, em tom amarelado, remonta a um passado remoto, reforçando essa origem no século XIX; as árvores em frente à fachada permitem perceber, na proporcionalidade, que se trata de uma edificação pequena, em relação às fábricas contemporâneas, preparadas para produzir milhões de litros por dia, o que reforça o efeito de real da imagem. A Fábrica Bohemia na internet busca transportar as significações de tradição para o meio digital: a primeira do mercado é também a precursora do formato de cervejaria virtual. Eis, abaixo, trecho do texto de apresentação do site:

"Neste site, você saberá mais sobre a primeira cerveja do Brasil e sobre a produção de cervejas de alta qualidade. Seu guia nesta visita é um personagem que é velho conhecido dos apreciadores de Bohemia: o Mestre Cervejeiro. Não se incomode se ele chamar você de "Aprendiz". Para ele, somos todos novatos quando o assunto é Bohemia.

Se for dirigir, não beba. Este site é melhor apreciado com fones de ouvido e resolução acima de 
O texto de abertura, além do caráter dos saberes a serem compartilhados - o saber sobre a história, o reconhecimento do valor da "alta qualidade", que é traduzida mercadologicamente pela categoria de cervejas premium - define a estratégia da interlocução. Há uma hierarquia bastante nítida nesse diálogo: o Mestre Cervejeiro, detentor dos conhecimentos, dos segredos sobre a cerveja, instaura a todos como "novatos", como "aprendizes". O jogo discursivo constrói essa identidade do sujeito do discurso e sua autoridade, uma forma de justificar o lugar destinado ao interlocutor, ao internauta - para o qual as escolhas e a forma de consumir as mensagens têm claras delimitações. A experiência proposta pressupõe um respeito devoto em relação à cultura da cerveja e de sua tradição; o site mobiliza signos que reforçam no plano visual essa "volta ao tempo", que nunca é completa em sua simulação, pois o próprio meio digital transmite em si a mensagem da contemporaneidade. Na última frase da abertura, além do imperativo regulatório ("se for dirigir, não beba"), a "sugestão" de consumo simbólico: sabemos então que a configuração ideal do computador equivale à forma adequada de servir a bebida. Experiência compartilhada de conhecedores e de aprendizes dessa mesma cultura, do prazer de consumir o líquido dourado e suas conotações transbordantes.

A navegação segue com uma imagem do cenário onde a fábrica se instala (Figura 1): em meio à natureza, uma edificação se destaca ao centro, plenamente harmonizada com o ambiente. A idéia de harmonia vem da combinação cromática sem contrastes: as cores frias, como um verde opaco e o marrom, o amarelo discreto de partes da vegetação, a cor dos tijolos, emolduram o tom dourado da fábrica, que se associa à iluminação solar, e, de forma um pouco menos direta, à cor da cerveja. A composição recupera imagens de quadros e pinturas da arte paisagística pré-moderna, que preservaram à posteridade a imagem de um mundo no qual a natureza é predominante, mesmo em lugares em que a presença humana começa a formar multidões, em comunidades, edificações, espaços de convivência construídos por suas mãos. Um vôo rasante aproxima o internauta do portão da fábrica, onde se vê o brasão com o logotipo da cerveja Bohemia e a inscrição que reitera sua origem temporal, e consequentemente, as significações de tradição, de permanência de um tempo passado: "Desde 1853".

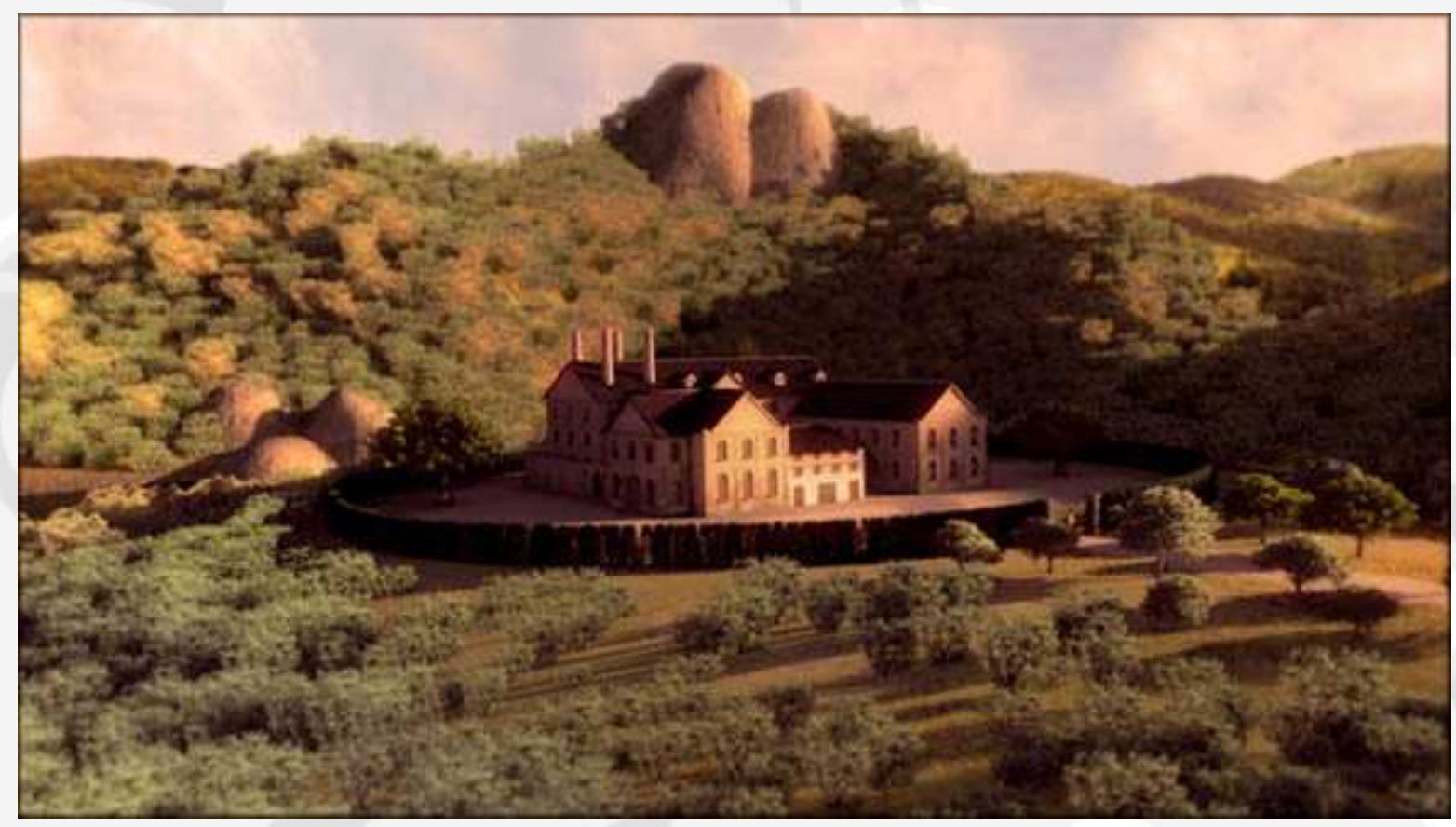

FIGURA 1 - Fachada da Fábrica Bohemia. (FONTE: www.bohemia.com.br) 
A proposta é a de instaurar o consumidor-internauta como um aprendiz do processo de produção da cerveja. A experiência da marca pressupõe uma visita à fábrica conduzida pela fala do Mestre Cervejeiro, o narrador que, por meio de sua fala, fornece informações e atribui valores para a compreensão das imagens de maneira reiterativa, direcionada. A primeira imagem da fábrica (Figura 2) deixa pistas que serão complementadas nas outras etapas da navegação: estamos tratando de uma organização espaçotemporal que sustenta paradoxos. O tempo representado na produção do espaço remonta aos primórdios da produção de cerveja, uma forma idealizada de ressignificar os processos produtivos ocultados pelo fetiche das imagens. Uma fábrica pequena, com paredes de tijolos à mostra, paralelepípedos na entrada, a natureza no entorno. A presença humana se restringe ao jogo enunciativo entre o narrador, o Mestre Cervejeiro, instaurado pela sua fala, e o sujeito projetado como seu interlocutor, o aprendiz que visita as instalações para conhecer o processo produtivo da cerveja - pressuposto pelo efeito de câmera subjetiva, da montagem que constrói o lugar do observador, o olhar simulado que determina o que é mostrado ao internauta. O tom dourado associado à cerveja estabelece um eixo cromático a partir do qual a estética das imagens se organiza em harmonia: até o céu com nuvens em tom salmão confirma a sensação de um tempo longínquo. As cores sustentam significados de uma estética de envelhecimento, que, na memória discursiva associada ao consumo de bebidas sofisticadas, remete ao aperfeiçoamento dos vinhos mais bem elaborados. Também recupera a estética de fotos antigas, amareladas com o passar dos anos, como vimos anteriormente. É um tempo passado, experimentado no presente, lido nas marcas com que tinge a espacialidade que remete à fábrica.

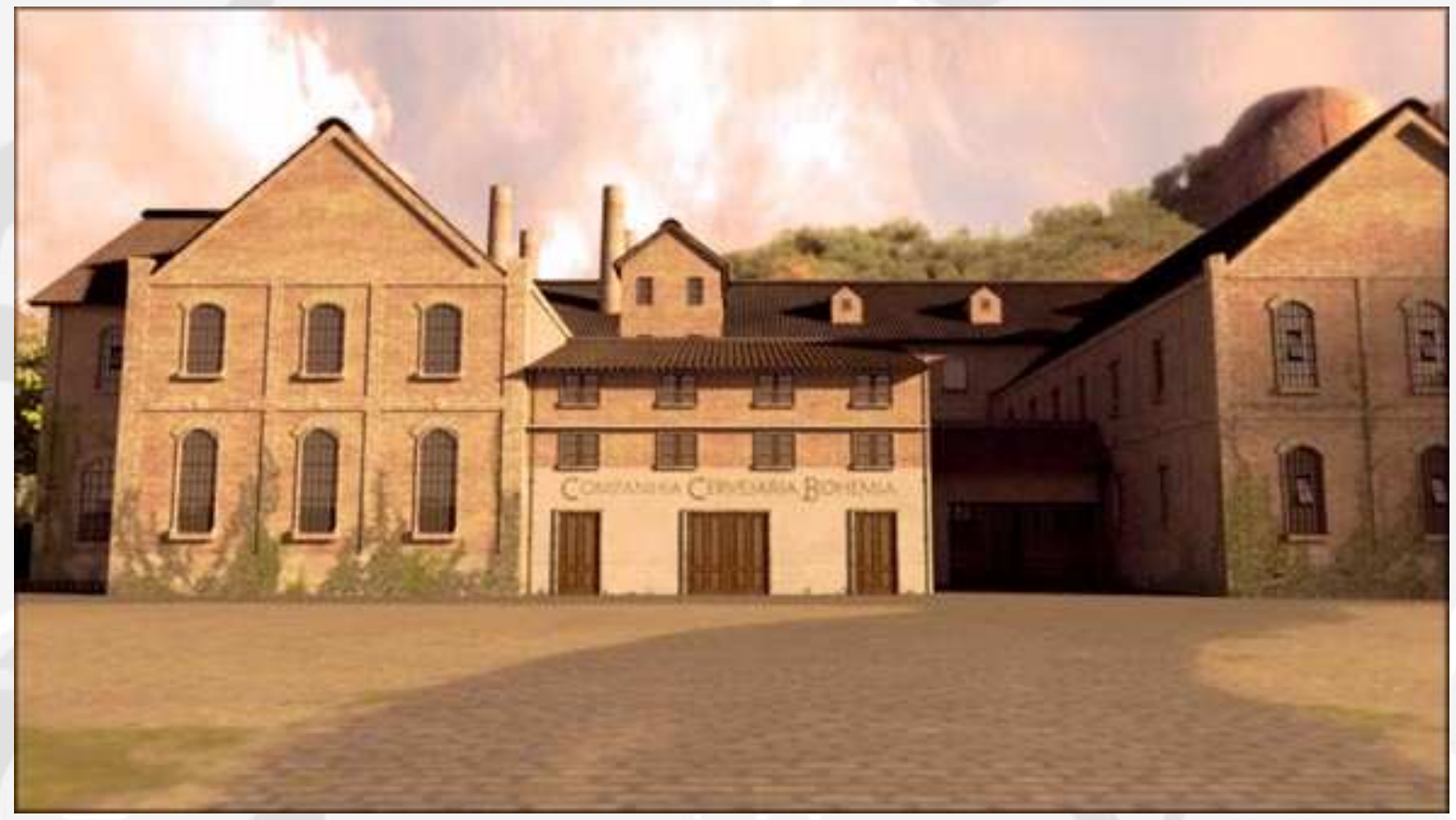

FIGURA 2 - Fachada da Fábrica Bohemia. FONTE: www.bohemia.com.br

Ao clicar na opção "fábrica", uma espécie de grande travelling, de viagem pelos caminhos que levam ao coração da fábrica, conduz o internauta até um saguão interno, que dá acesso ao processo fabril virtual da cerveja. É nesse ambiente que o internauta tem contato com as informações dos ingredientes básicos da cerveja, inseridas em um discurso que difunde a idéia de que o domínio desse saber é baseado em competência humana e procedimentos técnicos diferenciados: ao passo em que é revelado, cerca-se de magia. Os ingredientes para produzir uma cerveja são basicamente os mesmos. Porém, a expressão de sua procedência ("lúpulo inglês e maltes torrados europeus") significa o valor da qualidade, envolta de implícitos e subentendidos sobre a importância dessa origem para uma cerveja diferenciada, como é a cerveja Oaken, o produto destacado nessa navegação pela fábrica. No enunciado de Bohemia, refere-se a 
um conhecimento que é parcialmente compartilhado, pois se revela mais para sugerir o valor do enunciador do que propriamente capacitar o enunciatário a dialogar com esse saber, a compreender as possibilidades e alternativas que o envolvem. Imprime-se o discurso competente do Mestre Cervejeiro, que não justifica suas escolhas, mas que dá a elas o caráter simultaneamente científico e mítico: são derivadas de um conhecimento técnico reservado, personalizado, exclusivo (todos os "outros" são aprendizes), e também alquímico. Seguindo esse raciocínio, o passo a passo da fabricação (Figura 3) não tem como objetivo o compartilhamento desse saber, mas serve principalmente à afirmação do sujeito que representa a empresa. As qualificações do profissional o capacitam a exercer sua sensibilidade de maneira sofisticada: a função técnica é baseada no gerenciamento dos sentidos. Os odores, as cores, os sabores, manifestados na linguagem verbal, têm uma correspondência no plano da espacialidade. Os tons sobrepostos, a harmonia das cores, a sugestão de uma estética do "bom gosto" combinada com a referência à cor da bebida, sustentam essa maneira de traduzir para a mídia digital as impressões que se pretende que sejam consumidas juntamente com a cerveja.

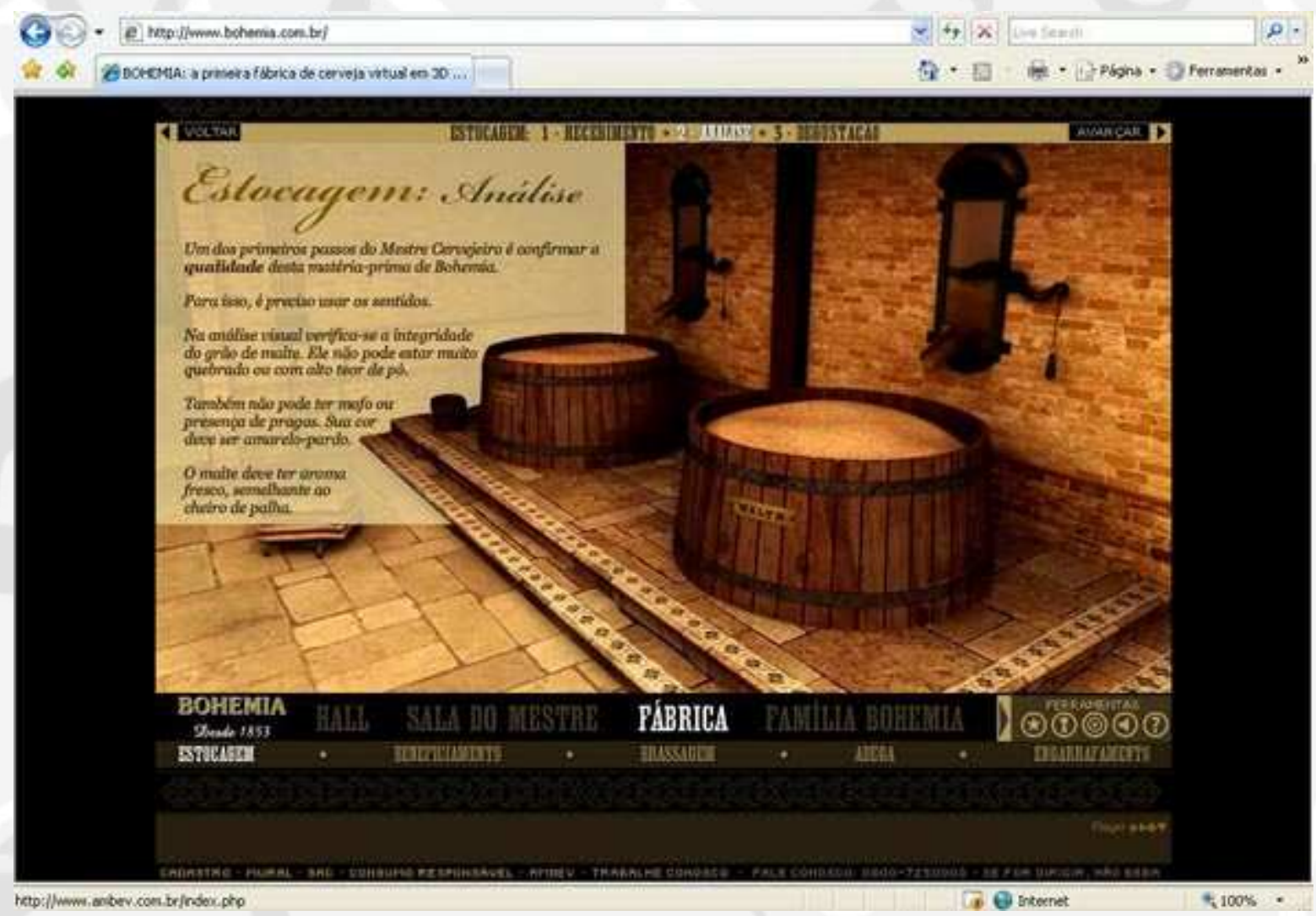

FIGURA 3 - A descrição de uma das etapas de produção da cerveja. (FONTE: www.bohemia.com.br)

No acesso à "Sala do Mestre" (Figura 4), reafirma-se um regime de visibilidade pautado pela ausência do corpo humano representado em cena: o traço humano se restringe à figura do narrador, pela sua fala e pelas legendas que a acompanham, não ocupando o espaço diegético. $\mathrm{O}$ corpo ausente, tanto nas instalações fabris quanto no escritório do Mestre Cervejeiro, convergem para uma ressignificação do trabalho nessa cenografia discursiva da produção de cerveja. $O$ trabalho material dá lugar à imaterialidade. No contexto do capitalismo contemporâneo, o reconhecimento dessa produção como trabalho imaterial é uma atribuição de valor elevado, de qualificação, de distinção. Essa reorganização do sistema produtivo serve a uma trama discursiva que configura o universo simbólico da mercadoria. A cerveja Oaken, uma cerveja de produção limitada, no plano discursivo apresenta-se para além de seu segmento. Envelhecida em barris de carvalho, dialoga com a cultura do vinho. O interlocutor é distinto pelo seu gosto apurado, pela capacidade de reconhecer o valor publicizado da mercadoria. Para isso, deve 
assumir durante o percurso o papel de aprendiz, de um sujeito em ausência de saber, que lhe será atribuído pelo representante de Bohemia. Aceitar a autoridade do Mestre Cervejeiro é assumir os valores intangíveis da mercadoria como concretos, comprovados, absolutos. A argumentação publicitária que qualifica o produto não o desconstrói, pelo contrário; superpõe mais uma camada estética que lhe permite identificar o valor do sabor, o gosto calcado no repertório cultural, questão analisada por Pierre Bourdieu em sua obra A distinção (2007).

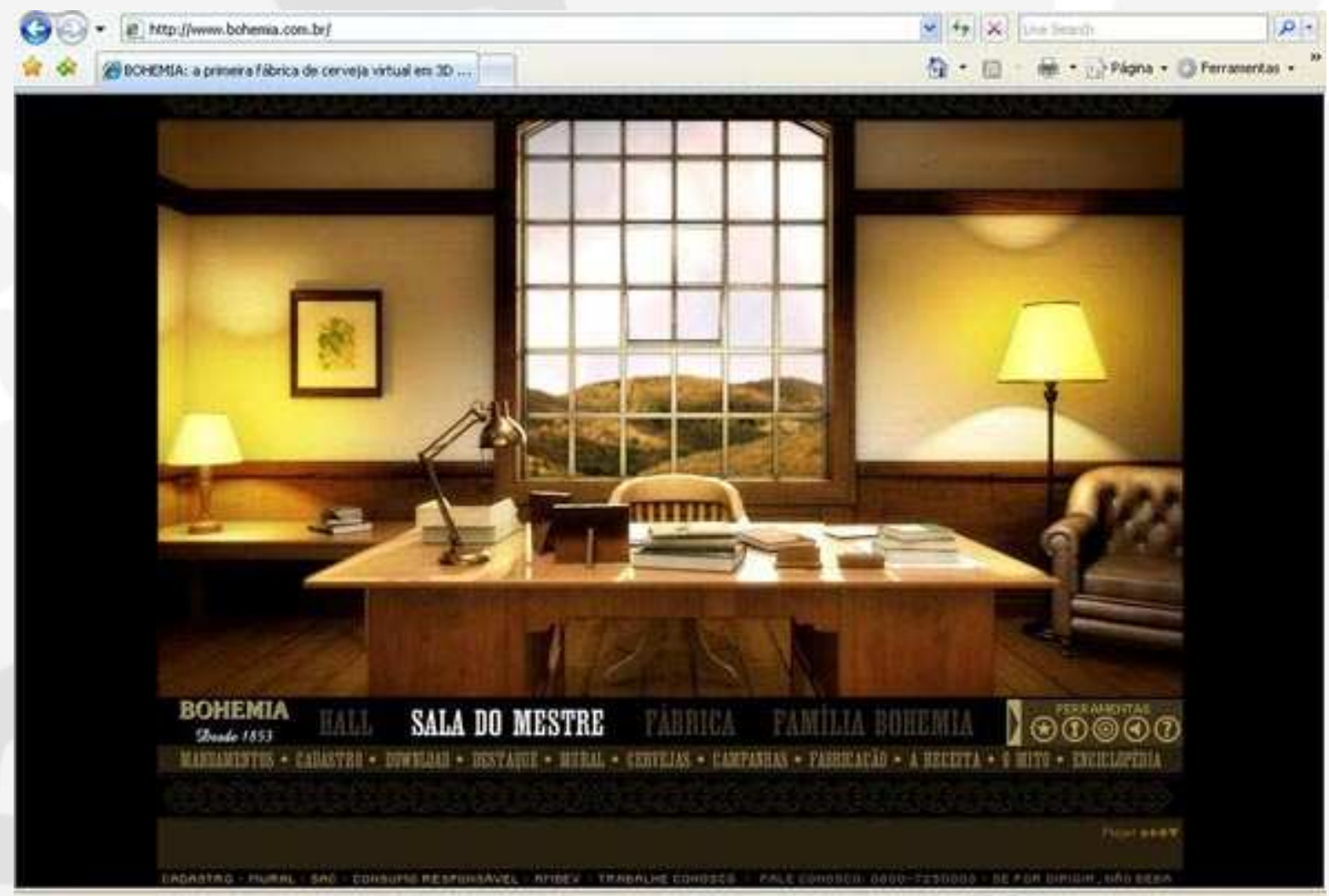

(1) internst

FIGURA 4 - Visão da Sala do Mestre Cervejeiro, uma das opções de visita ao mundo de Bohemia. (FONTE: www.bohemia.com.br)

O aprendizado, o conhecimento destinado ao aprendiz, edifica o ethos do enunciador: o discurso atesta a virtude de quem é responsável por todos os processos demonstrados - divididos em 20 etapas, do estoque dos ingredientes até o engarrafamento da cerveja. Assegura-lhe um traço de caráter de autoridade; essa ascendência do Mestre Cervejeiro legitima uma marca enunciativa da organização dos trajetos possíveis, das opções de navegação. O processo tem uma ordem, é numerado em sequência; cada ambiente circunscreve uma liberdade relativa para o interlocutor aprender na ordem que achar melhor. Porém, essa relação hierárquica entre enunciador e enunciatário se mantém; a narrativa de publicização na web incorpora um sentido de flexibilidade, de interação mais ampla do que qualquer mídia tradicional. Porém, no caso da Fábrica Bohemia, os caminhos são muito bem delimitados; o tom do discurso se sustenta como um jogo de poder onde o enunciador detém o conhecimento e instaura o enunciatário como destituído do mesmo. A cada etapa, questões sobre o processo de fabricação da cerveja, com respostas a partir de alternativas, colocam-se como uma forma do narrador reconhecer ou não se o seu interlocutor está se transformando em um iniciado em seu universo de saber.

Há uma rede de significações em torno do campo místico, religioso, que atravessa a caracterização do personagem Mestre Cervejeiro, por sua sensibilidade aguçada e sua competência, quase mágica, divina, para produzir as diversas combinações de elementos que vão resultar na "família" de produtos Bohemia 
(Pilsen, a mais comum e com preço mais acessível; Oaken, Weiss, Escura, Confraria, as cervejas de composição diferenciada, com valor mais elevado). As significações derivadas do campo religioso se amplificam quando o internauta acessa a área em que há informações distintas para o consumo das submarcas de Bohemia. Cada uma delas tem um "ritual" a ser cumprido, para a conservação, para ser servida e degustada. Seguir o ritual é ser um bom aprendiz; vivenciar o ritual ganha conotações de uma experiência sensível elevada, mística. Para que a educação para o ritual se realize, o internauta encontra no site filmes que, em tom didático, demonstram como a cerveja deve ser consumida, não somente como uma bebida, mas como uma experiência carregada de simbolismo, de atribuições intangíveis. Assim como esse material, que pode ser baixado, a opção de downloads permite que o consumidor se municie de imagens que permitem alimentar, principalmente, a visualidade desse consumo. Imagens da fábrica, papéis de parede, descanso de tela, são elementos que pretendem estender a permanência dessa cena enunciativa em torno da marca Bohemia na vida de seu consumidor, na busca pela inserção em sua vida cotidiana. Todo o consumir insinuado pelo processo publicitário ambiciona a consumação, a ação pragmática de seu público-alvo. Todavia, na sociedade de consumo em que vivemos, são tantas as propostas, que o indivíduo, multiplicado por inúmeros pontos de encontro (DI NALLO, 1999) em que se instaura como consumidor, transita entre identificações derivadas do universo simbólico de marcas das mais variadas e do comportamento sociocultural que gravita em torno das mercadorias. A estética da mercadoria, que amplifica suas possibilidades de consumo, pelas características da publicização contemporânea, difunde-se por estratégias que, de certa forma, podem ser entendidas como formas de reterritorialização das práticas de consumo. A cerveja é consumida na virtualidade da propaganda televisiva, na mídia digital, no pano de fundo do computador, e, até, servida bem gelada em uma mesa de bar.

\section{Considerações finais: sobre os aspectos imateriais da produção e do consumo}

O caso da Fábrica Bohemia reforça a questão já consagrada a respeito da esfera intangível do consumo contemporâneo, da maneira como a estética estabelece redes de significações a partir da base material das mercadorias. E também lança questões interessantes sobre o lugar da produção, a maneira como o mundo do trabalho é traduzido para servir a esse universo simbólico das mercadorias. Se a fantasmagoria, o fetiche das mercadorias, desvincula a relação imediata entre o produtor e a sua produção, através de processos de especialização, de divisão do trabalho, de mercadorização da força de trabalho, a publicização dessas mercadorias vai estabelecer um novo vínculo entre o produto e a produção; esta última transforma-se em um subproduto, uma derivação do bem de consumo. Nessa forma de mercadorização do processo produtivo, o trabalhador do chão da fábrica simplesmente desaparece, como uma concreta realização do caráter imaterial do consumo. Com a desaparição do corpo representado do trabalhador, abre-se espaço para que nós, consumidores dessa experiência em torno da mercadoria nos instauremos como trabalhadores da mesma. De que forma? Ao propagar os códigos estéticos da marca; ao praticar e exigir dos outros o respeito à liturgia de seu universo; ao disseminar as significações da experiência para as pessoas com as quais se relaciona. Conduzidos pelo Mestre Cervejeiro, podemos ser trabalhadores em um sentido lúdico, em um mundo editado pela lógica da comunicação persuasiva; quanto à mão de obra que efetivamente faz da fábrica uma produtora de cerveja em larga escala, em uma megaindústria de capital transnacional, resta a desaparição, a exclusão simbólica, e a possibilidade de se alinhar à equipe de consumidores-trabalhadores. As mediações e midiatizações do trabalho produzem significações complexas dessa esfera fundamental da ação humana na contemporaneidade. Esse mundo alardeado como em extinção nunca esteve tão em evidência, seja pela maneira como sofre, de maneira brutal, a consequência pelas falhas do sistema econômico vigente, seja pela forma como é traduzido para dar novas nuances ao plano imaterial do consumo das mercadorias. 


\section{Bibliografia:}

ANTUNES, R. Adeus ao trabalho? Ensaio sobre as metamorfoses e a centralidade do mundo do trabalho. São Paulo: Cortez / Unicamp, 1995.

APPADURAI, A. "Disjunção e diferença na economia cultural global”. In: FEATHERSTONE, M. (org). Cultura global: nacionalismo, globalização e modernidade. Petrópolis: Vozes, 1999, pp.311-327.

BAITELLO JUNIOR, N. A era da iconofagia: ensaios de comunicação e cultura. São Paulo: Hacker, 2005.

BAKHTIN, M (Volochinov). Marxismo e filosofia da linguagem. São Paulo: Hucitec, 1997.

BARTHES, R. El susurro del lenguaje: más allá de la palabra y de la escritura. Barcelona: Paidós, 1994.

BAUDRILLARD, J. O sistema dos objetos. São Paulo: Perspectiva, 2006.

BAUMAN, Z. Modernidade líquida. Rio de Janeiro: Zahar, 2001.

BOURDIEU, P. A distinção: crítica social do julgamento. São Paulo: Edusp; Porto Alegre: Zouk, 2007.

DI NALLO, E. Meeting points: soluções de marketing para uma sociedade complexa. São Paulo: Marcos Cobra, 1999.

FONTENELLE, I.A. O nome da marca: McDonald's, fetichismo e cultura descartável. São Paulo: Boitempo, 2002.

FRANÇA, V. "Sujeito da comunicação, sujeitos em comunicação". In: GUIMARÃES, C., FRANÇA, V. (orgs). Na mídia, na rua: narrativas do cotidiano. Belo Horizonte: Autêntica, 2006, p.61-88.

GORZ, A. O imaterial: conhecimento, valor e capital. São Paulo: Annablume, 2005.

HARVEY, D. A produção capitalista do espaço. São Paulo: Annablume, 2006.

HAUG, W. Crítica da estética da mercadoria. São Paulo: Ed. Unesp, 1997.

IANNI, O. Teorias da globalização. Rio de Janeiro: Civilização Brasileira, 2002.

LANDOWSKI, E. Presenças do outro: ensaios de sociossemiótica. São Paulo: Perspectiva, 2002.

MARX, K. O capital: extratos por Paul Lafargue. São Paulo: Conrad, 2004.

PARENTE, A. O virtual e o hipertextual. Rio de Janeiro: Pazulin, 1999.

\section{Notas:}

A primeira versão deste artigo foi apresentada no Grupo de Trabalho "Cultura das Mídias", do XVIII Encontro da Compós, na PUC-MG, Belo Horizonte, MG, em junho de 2009. 
(1) Fonte: http://www.ambev.com.br/emp_04.htm, acessado em 13 de fevereiro de 2009.

(2) Essa medida, que visa cumprir a legislação sobre o consumo de bebidas alcoólicas, restrito aos maiores de 18 anos, é um recurso limitado, pois depende somente da declaração do próprio usuário.

\section{Mini Currículo :}

Vander Casaqui é doutor em Ciências da Comunicação pela ECA-USP; Docente do Programa de Mestrado em Comunicação e Práticas de Consumo, da Escola Superior de Propaganda e Marketing (ESPM-SP). E-mail: vcasaqui@espm.br 